\title{
Evaluation of Bone Mineral Density in Patients with Chronic Low Back Pain
}

\author{
Osama Al-Saeed ${ }^{1}$, Ahmed Mohammed ${ }^{2}$, Fawaz Azizieh ${ }^{3}$, Renu Gupta ${ }^{1}$ \\ ${ }^{1}$ Department of Radiology, Faculty of Medicine, Kuwait University, Kuwait \\ ${ }^{2}$ Medical Education Unit, Faculty of Medicine, Kuwait University, Kuwait \\ ${ }^{3}$ Gulf University of Science and Technology, Kuwait
}

Study Design: This was designed as a retrospective study.

Purpose: We investigated the relationship between bone mineral density (BMD) and chronic lower back pain (LBP).

Overview of Literature: In spite of a large number of epidemiological surveys on the prevalence of LBP and BMD measurements completed separately in the general population, the relationship between the two has not been well documented.

Methods: The study included 171 patients with chronic LBP who underwent the BMD study. The control group was selected from our database regarding BMD without LBP.

Results: A total of 678 subjects, aged 18 to 100 years (mean, $49.9 \pm 12.9$ years) were included in the study, $25 \%$ ( $n=171$ ) of the subjects had LBP. Compared to those patients without LBP, patients exhibiting LBP had statistically significant lower mean weight, hip and spine BMD and T-score. Lower BMD and T-scores were significant regardless of the age group, gender, menopausal status, and obesity classification.

Conclusions: Chronic LBP has a negative correlation with hip and spine bone mineral density.

Keywords: Lumbar vertebrae; Hip; Bone density; Absorptiometry, Photon

\section{Introduction}

Musculoskeletal disorders are a major leading cause of long term disability, days of restricted activity and health care utilization [1]. Of the musculoskeletal conditions, osteoporosis and lower back pain (LBP) are two, which cause a major burden on individuals as well as health and social care systems [2]. Osteoporosis is a major risk factor for hip and vertebral fractures which are associated with mortality and permanent loss of function [2]. LBP is the most common musculoskeletal condition affecting a significant amount of people and approximately $4 \%$ to $33 \%$ of the population at any given point [2]. Not surprisingly, lifetime prevalence of LBP ranges from $13.8 \%$ to $84 \%$ in middle-aged and older people [3-7]. LBPs associated costs with regards to society are substantial and show a yearly increase, having a significant impact on medical and social resources in all industrialized nations [1].

In spite of a large number of epidemiological surveys on the prevalence of LBP and bone mineral density (BMD) measurements completed separately in the general population, the relationship between the two has not been well documented. The authors of several studies concluded that they were unable to find any evidence

Received Feb 15, 2012; Revised Apr 17, 2012; Accepted Apr 26, 2012

Corresponding author: Renu Gupta

Department of Radiology, Kuwait University,

P. O. Box: 24923, Code No 13110, Kuwait

Tel: +965-66685157, Fax: +965-25330473, E-mail: renu@hsc.edu.kw 
for such a relationship [8-10]. Others found BMD to be higher $[11,12]$ or lower $[13,14]$ in individuals suffering from LBP than in controls. The purpose of this study was to investigate whether low BMD values could be associated with the occurrence of LBP.

\section{Materials and Methods}

The study included 171 patients exhibiting chronic LBP for more than 6 weeks who underwent a BMD study. The available radiographs were reviewed to assess the presence of vertebral deformities as per the method described by McCloskey et al. [15]. The control group of 507 patients was selected from our database regarding BMD without LBP. The exclusion criteria were those having a medical history known to affect bone metabolism on the basis of information obtained by the referring consultant. Diseases and the number of subjects excluded were endocrine abnormalities in the parathyroid and thyroid glands $(n=113)$, rheumatoid arthritis $(n=44)$, renal disease $(n=87)$, steroid treatment $(n=186)$, liver and kidney transplant $(n=32)$, children $(n=82)$, sickle cell disease $(\mathrm{n}=104)$, and systemic lupus erythematosus $(\mathrm{n}=38)$. Subjects with a history of medication such as corticosteroids and hormone replacement therapy were also excluded from the study. Women were also divided in two groups premenopausal and postmenopausal. Collecting accurate data on the date of onset for menopause was not possible as patients were guessing when asked to recall the date or gave an imprecise date. A practical approach was to set an arbitrary cut off point of 50 years, which should separate most of the postmenopausal women from the premenopausal women.

Body weight was measured to the nearest $0.1 \mathrm{~kg}$ on an electronic beam scale. Height was measured to the nearest $0.5 \mathrm{~cm}$ using a stadiometer. Also, body weight and height were each measured twice per time point, and the average of the 2 measures was used. Body mass index (BMI) was calculated as weight $(\mathrm{kg})$ divided by height squared $\left(\mathrm{m}^{2}\right)$, and was used to categorize the participants according to the criteria by the World Health Organization (WHO): normal weight, $\mathrm{BMI}<24.9 \mathrm{~kg} / \mathrm{m}^{2}$; overweight, $25<\mathrm{BMI}<29.9 \mathrm{~kg} / \mathrm{m}^{2}$; obesity, BMI $>30 \mathrm{~kg} / \mathrm{m}^{2}$.

BMD was measured at the lumbar spine (L1-L4) and total left hip using a dual-energy X-ray absorptiometry (Hologic QDR 4500A, Hologic Inc., Waltham, MA, USA) with a precision (coefficient of variation) of $0.7 \%$. The
Table 1. Anthropometric values of individuals by low back pain

\begin{tabular}{lccl|}
\multicolumn{1}{l}{ Characteristics } & LBP $(-)$ & $\operatorname{LBP}(+)$ & $p$-value \\
\hline Age $(\mathrm{yr})$ & $49.5 \pm 12.8$ & $50.9 \pm 13.4$ & 0.21 \\
\hline Height $(\mathrm{cm})$ & $158.8 \pm 8$ & $158.3 \pm 7.4$ & 0.43 \\
\hline Weight $(\mathrm{kg})$ & $79.6 \pm 15.4$ & $76.8 \pm 13.8$ & 0.04 \\
\hline BMI & $31.6 \pm 6.2$ & $30.8 \pm 5.9$ & 0.13 \\
\hline BMD hip & $0.99 \pm 0.13$ & $0.92 \pm 0.15$ & 0.0001 \\
\hline BMD spine & $1.0 \pm 0.13$ & $0.94 \pm 0.14$ & 0.0001 \\
\hline Hip T score & $0.3 \pm 1.03$ & $-0.16 \pm 1.21$ & 0.0001 \\
\hline Spine T score & $-0.4 \pm 1.14$ & $-0.94 \pm 1.24$ & 0.0001 \\
\hline
\end{tabular}

$\operatorname{LBP}(-)$, without low back pain; $\operatorname{LBP}(+)$, with low back pain; BMI, body mass index; $\mathrm{BMD}$, bone mineral density.

scanner is calibrated daily against the standard calibration block supplied by the manufacturer in order to control possible baseline drift.

Data analysis was performed using the Statistical Package for the Social Sciences designed for Windows ver. 19.0 (IBM, Armonk, NY, USA). When appropriate, data were presented using the mean standard deviation. Student's $t$-test was used to assess the statistical significance of difference in anthropometric values for individuals by LBP, stratified age groups, gender, menopausal status and BMI. A $p$-value of $<0.05$ was considered statistically significant.

\section{Results}

A total of 678 subjects, aged 18 to 100 years (mean, $49.9 \pm 12.9$ years $)$ were included in the study. $25 \%(n=171)$ of the subjects had LBP (19\% males and $81 \%$ females), and $75 \%(n=507)$ had no LBP ( $16 \%$ males and $84 \%$ females). In patients with LBP, single vertebral deformities were found in three $(9.4 \%)$ males and 11 (7.9\%) females, while multiple deformities were found in one $(3.1 \%)$ male and five (3.6\%) females.

Compared to those patients without LBP, patients with LBP had statistically significant lower mean weight $(p=0.04)$, hip and spine BMD $(p=0.0001)$ and lower mean hip and spine T-scores $(p=0.0001)$ (Table 1$)$.

The subjects were divided into four groups as per age: $<40$ years $(\mathrm{n}=135), 40-49$ years $(\mathrm{n}=225), 50-59$ years $(n=147)$, and $\geq 60$ years $(n=171)$. The subjects within any of the age groups did not show any statistical significant differences in age, height, weight or BMI (Table 2). How- 


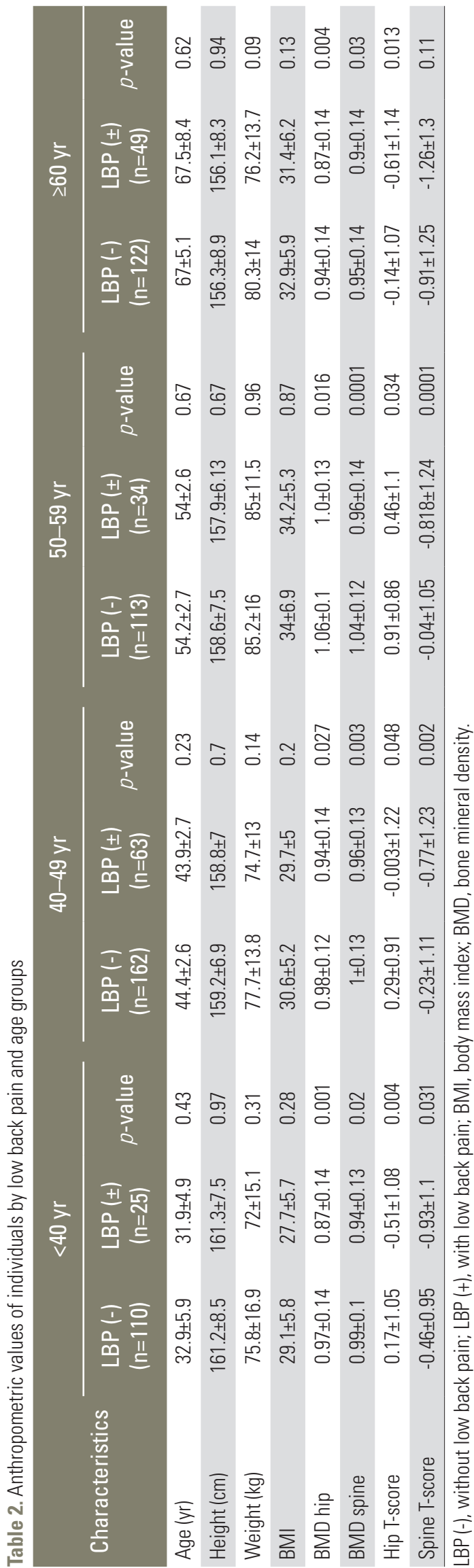

ever, the differences in hip and spine BMDs and T-scores were significant and lower in patients with LBP compared to patients without LBP.

There was a difference between those patients with LBP and those without LBP according to their gender. Male, but not female, patients with LBP were older and lighter and less obese than those patients without LBP with a mean age of $59.8 \pm 16.4$ years vs. $52.7 \pm 15.8$ years $(p=0.037)$, a mean weight of $76.2 \pm 10.4 \mathrm{~kg}$ vs. $83.6 \pm 12.4 \mathrm{~kg}(p=0.004)$, and a mean BMI of $27.5 \pm 4$ vs. $29.3 \pm 3.9$ ( $p=0.033$ ). Both males and females with LBP had lower hip and spine BMDs and T-scores (Table 3).

In both groups, premenopausal and postmenopausal women and women with LBP had comparable age, height, weight as well as BMI values but lower hip and spine BMDs and T-scores compared to those women without LBP (Table 4). Grouping the subjects according to their BMI using the criteria by the WHO showed that patients with LBP whether they were normal, overweighed, or obese had lower hip and spine BMDs and Tscores compared to those patients without LBP (Table 5).

\section{Discussion}

The study question has been addressed by a number of studies but with conflicting results. In addition, this study confirmed that chronic LBP subjects have statistically significant lower mean hip and spine BMDs and T-scores as compared to those patients without LBP. No association between the prevalence of LBP and BMD was found by Zetterberg et al. [8], Nicholson et al. [9], and more recently Ahn and Song [10]. Zetterberg et al. [8] investigated the incidence of LBP in 80 hip fracture patients between the ages of 50 to 99 years, and radiographically evaluated vertebral fractures. The investigators found no relation between longstanding LBP and spinal osteoporosis in the elderly as the incidence of LBP in the 103 controls, 70 to 75 years of age, was twice as much in the hip fracture patients [8]. Nicholson et al. [9] investigated an association between LBP, based on the interview, and vertebral deformity, assessed radiographically, in 222 women, aged 50 to 82 years, and found that even with subjects who displayed significant deformity as well as low BMD scores did not have an increased prevalence of LBP. Ahn and Song [10], studied 134 postmenopausal women where approximately $70 \%$ of them experienced LBP for more than 1 day, and found no association between LBP 
Table 3. Anthropometric values of individuals by low back pain and gender

\begin{tabular}{|c|c|c|c|c|c|c|}
\hline \multirow[b]{2}{*}{ Characteristics } & \multicolumn{3}{|c|}{ Males } & \multicolumn{3}{|c|}{ Females } \\
\hline & $\begin{array}{l}\operatorname{LBP}(-) \\
(n=80)\end{array}$ & $\begin{array}{c}\operatorname{LBP}(+) \\
(\mathrm{n}=32)\end{array}$ & $p$-value & $\begin{array}{l}\operatorname{LBP}(-) \\
(n=427)\end{array}$ & $\begin{array}{l}\operatorname{LBP}(+) \\
(n=139)\end{array}$ & $p$-value \\
\hline Age (yr) & $52.7 \pm 15.8$ & $59.8 \pm 16.4$ & 0.037 & $48.9 \pm 12.1$ & $48.9 \pm 11.8$ & 0.99 \\
\hline Height (cm) & $168.94 \pm 8$ & $166.8 \pm 7.3$ & 0.18 & $156.9 \pm 6.5$ & $156.3 \pm 6$ & 0.33 \\
\hline Weight (kg) & $83.6 \pm 12.4$ & $76.2 \pm 10.4$ & 0.004 & $78.8 \pm 15.8$ & $76.9 \pm 14.5$ & 0.22 \\
\hline BMI & $29.3 \pm 3.9$ & $27.5 \pm 4$ & 0.033 & $32.1 \pm 6.4$ & $31.6 \pm 5.9$ & 0.41 \\
\hline BMD hip & $1.05 \pm 0.14$ & $0.93 \pm 0.15$ & 0.0001 & $0.97 \pm 0.13$ & $0.92 \pm 0.15$ & 0.0001 \\
\hline BMD spine & $1.03 \pm 0.13$ & $0.94 \pm 0.15$ & 0.002 & $1 \pm 0.13$ & $0.94 \pm 0.13$ & 0.0001 \\
\hline Hip T-score & $0.227 \pm 0.92$ & $-0.52 \pm 1$ & 0.0001 & $0.314 \pm 1.06$ & $-0.07 \pm 1.2$ & 0.001 \\
\hline Spine T-score & $-0.49 \pm 1.17$ & $-1.07 \pm 1.3$ & 0.023 & $-0.39 \pm 1.14$ & $-0.91 \pm 1.2$ & 0.0001 \\
\hline
\end{tabular}

$\operatorname{LBP}(-)$, without low back pain; $\operatorname{LBP}(+)$, with low back pain; $B M I$, body mass index; $B M D$, bone mineral density.

Table 4. Anthropometric values of individuals by low back pain and menopausal status

\begin{tabular}{|c|c|c|c|c|c|c|}
\hline \multirow[b]{2}{*}{ Characteristics } & \multicolumn{3}{|c|}{$\leq 50 \mathrm{yr}$} & \multicolumn{3}{|c|}{$>50 \mathrm{yr}$} \\
\hline & $\begin{array}{l}\operatorname{LBP}(-) \\
(n=238)\end{array}$ & $\begin{array}{c}\operatorname{LBP}(+) \\
(\mathrm{n}=79)\end{array}$ & $p$-value & $\begin{array}{l}\operatorname{LBP}(-) \\
(n=189)\end{array}$ & $\begin{array}{c}\operatorname{LBP}(+) \\
(\mathrm{n}=60)\end{array}$ & $p$-value \\
\hline Age (yr) & $40.1 \pm 6.7$ & $40.4 \pm 6.5$ & 0.74 & $59.9 \pm 7.5$ & $60 \pm 6.8$ & 0.93 \\
\hline Height (cm) & $158.4 \pm 6.1$ & $158.1 \pm 5.7$ & 0.69 & $155 \pm 6.4$ & $154 \pm 5.5$ & 0.24 \\
\hline Weight $(\mathrm{kg})$ & $76.1 \pm 15$ & $73.6 \pm 13.6$ & 0.2 & $82.3 \pm 16$ & $81.4 \pm 14.6$ & 0.69 \\
\hline $\mathrm{BMI}$ & $30.3 \pm 5.6$ & $29.5 \pm 5.3$ & 0.26 & $34.3 \pm 6.8$ & $34.3 \pm 5.8$ & 0.99 \\
\hline BMD hip & $0.96 \pm 0.11$ & $0.92 \pm 0.14$ & 0.01 & $0.99 \pm 0.14$ & $0.92 \pm 0.15$ & 0.004 \\
\hline BMD spine & $1.01 \pm 0.12$ & $0.96 \pm 0.13$ & 0.001 & $0.98 \pm 0.14$ & $0.92 \pm 0.14$ & 0.001 \\
\hline Hip T-score & $0.234 \pm 0.95$ & $-0.1 \pm 1.2$ & 0.027 & $0.41 \pm 1.2$ & $-0.36 \pm 1.3$ & 0.014 \\
\hline Spine T-score & $-0.275 \pm 1.02$ & $-0.76 \pm 1.17$ & 0.001 & $-0.52 \pm 1.3$ & $-0.036 \pm 0.17$ & 0.002 \\
\hline
\end{tabular}

$\operatorname{LBP}(-)$, without low back pain; LBP (+), with low back pain; BMI, body mass index; BMD, bone mineral density.

status and fracture risk status but between LBP status and menopausal symptoms and health habits.

Manabe et al. [11], in a cross-sectional study, investigated 2,244 women, aged 25 to 85 years, and found that LBP, based on a self-administered questionnaire, is associated with high BMD measurements, concluding that high BMD is as important as low BMD as a cause for musculoskeletal symptoms and disabilities. Snider et al. [12], studied 63 individuals, 16 of which had LBP, and showed that patients with LBP had significantly higher $B M D$ values at the lumbar spine in comparison to the individuals without LBP.

If the classical definition of osteoporosis (a condition which leads to an increased risk of fractures) is to be considered, one would expect that the higher the incidence of LBP, the greater the prevalence of hip and vertebral fractures. Such an expected relation was found by Kuroda et al. [13] and Park et al. [14]. Kuroda et al. [13] followed up 818 postmenopausal women with and without LBP for a number of years, and demonstrated that the LBP group displayed significantly lower BMD values in the lumbar spine and hip as well as a higher number of prevalent vertebral fractures than those without LBP. Park et al. [14] examined the medical records of 78 postmenopausal women hospitalized for LBP, and found that despite having the same treatment outcomes, women with low BMD values typically had longer hospital stays and higher pain scores than those with normal BMD values [14].

An explanation for the varied findings in all the studies could be due to incomparable age groups, inaccurate 


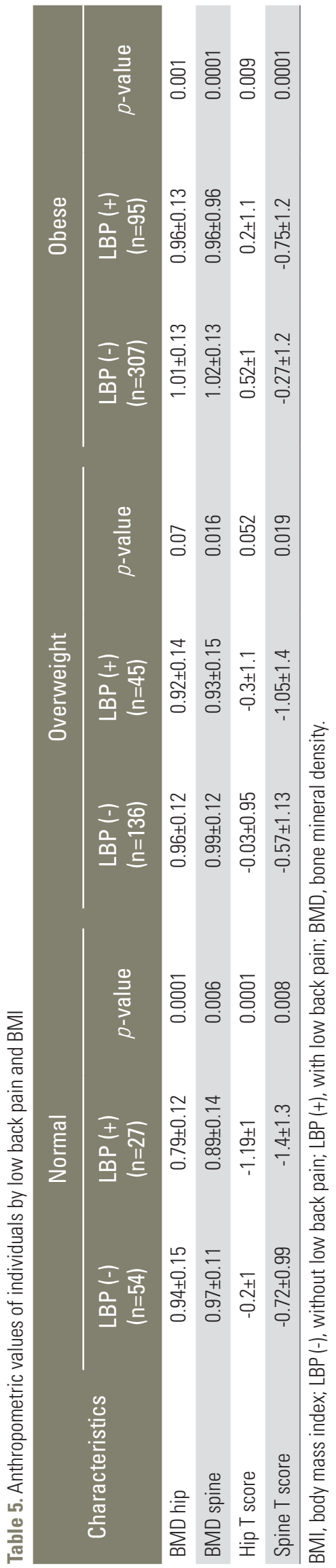

recall of LBP history, inconsistent definition of or the methods used to classify LBP, or lack of exclusion criteria for the study subjects in some studies. Furthermore, this study has its own limitations. There is a selection bias driven by the method of data collection being retrospective, and that the subjects were recruited at one center. Furthermore, BMD measurements for the lumbar spine are frequently affected by deformities and degenerative changes, which leads to a falsely elevated spinal BMD on assessment of bone mass [16]. Moreover, the prevalence of these vertebral deformities rises with age [9]. Many studies have shown a positive association between vertebral deformity and LBP, particularly, in elderly people [17-19].

In this study, a higher percentage of subjects without LBP were overweight or obese, but the difference was not statistically significant. Lower BMDs and T-scores were significant, regardless of the age group, gender, menopausal status, or obesity classification. Only male patients with LBP were older than those patients without LBP having a mean age of $59.8 \pm 16.4$ years vs. $52.7 \pm 15.8$ years ( $p=0.037)$. Generally, the occurrence of LBP and loss of $\mathrm{BMD}$ is higher in older individuals. LBP restricts some daily activities, exerting indirect influence on BMD.

Obesity is a known risk factor for LBP [20] and has a negative [21-23], positive [24-26] or no relationship [22] with BMD. This study demonstrated that males with LBP were less obese, while females were not. When divided into age groups, the difference in weight and obesity in males was normalized. BMD was highest in the obese group, higher in the overweight group and lowest in the normal weight group; thus, supporting the protective effect of obesity on BMD. Furthermore, vertebral deformities and degenerative changes falsely elevate spinal BMD [15], and are expected in the study subjects. The data showed that BMD was lower in the LBP group, in spite of the possible overestimation of spinal BMD. Hence, such changes were not assessed radiographically.

\section{Conclusions}

Chronic LBP has a negative correlation with hip and spine BMD. 


\section{Conflict of Interest}

No potential conflict of interest relevant to this article was reported.

\section{References}

1. Badley EM, Rasooly I, Webster GK. Relative importance of musculoskeletal disorders as a cause of chronic health problems, disability, and health care utilization: findings from the 1990 Ontario Health Survey. J Rheumatol 1994;21:505-14.

2. Woolf AD, Pfleger B. Burden of major musculoskeletal conditions. Bull World Health Organ 2003;81:64656.

3. Cassidy JD, Carroll LJ, Cote P. The Saskatchewan health and back pain survey. The prevalence of low back pain and related disability in Saskatchewan adults. Spine (Phila Pa 1976) 1998;23:1860-6.

4. Deyo RA, Tsui-Wu YJ. Descriptive epidemiology of low-back pain and its related medical care in the United States. Spine (Phila Pa 1976) 1987;12:264-8.

5. Hillman M, Wright A, Rajaratnam G, Tennant A, Chamberlain MA. Prevalence of low back pain in the community: implications for service provision in Bradford, UK. J Epidemiol Community Health 1996;50:347-52.

6. Lau EM, Egger P, Coggon D, Cooper C, Valenti L, O'Connell D. Low back pain in Hong Kong: prevalence and characteristics compared with Britain. J Epidemiol Community Health 1995;49:492-4.

7. Papageorgiou AC, Croft PR, Ferry S, Jayson MI, Silman AJ. Estimating the prevalence of low back pain in the general population. Evidence from the South Manchester Back Pain Survey. Spine (Phila Pa 1976) 1995;20:1889-94.

8. Zetterberg C, Mannius S, Mellstrom D, Rundgren A, Astrand K. Osteoporosis and back pain in the elderly. A controlled epidemiologic and radiographic study. Spine (Phila Pa 1976) 1990;15:783-6.

9. Nicholson PH, Haddaway MJ, Davie MW, Evans SF. Vertebral deformity, bone mineral density, back pain and height loss in unscreened women over 50 years. Osteoporos Int 1993;3:300-7.

10. Ahn S, Song R. Bone mineral density and perceived menopausal symptoms: factors influencing low back pain in postmenopausal women. J Adv Nurs
2009;65:1228-36.

11. Manabe T, Takasugi S, Iwamoto Y. Positive relationship between bone mineral density and low back pain in middle-aged women. Eur Spine J 2003;12:596-601.

12. Snider KT, Johnson JC, Degenhardt BF, Snider EJ. Low back pain, somatic dysfunction, and segmental bone mineral density T-score variation in the lumbar spine. J Am Osteopath Assoc 2011;111:89-96.

13. Kuroda T, Shiraki M, Tanaka S, Shiraki Y, Narusawa K, Nakamura T. The relationship between back pain and future vertebral fracture in postmenopausal women. Spine (Phila Pa 1976) 2009;34:1984-9.

14. Park JJ, Shin J, Youn Y, et al. Bone mineral density, body mass index, postmenopausal period and outcomes of low back pain treatment in Korean postmenopausal women. Eur Spine J 2010;19:1942-7.

15. McCloskey EV, Spector TD, Eyres KS, et al. The assessment of vertebral deformity: a method for use in population studies and clinical trials. Osteoporos Int 1993;3:138-47.

16. von der Recke P, Hansen MA, Overgaard K, Christiansen $\mathrm{C}$. The impact of degenerative conditions in the spine on bone mineral density and fracture risk prediction. Osteoporos Int 1996;6:43-9.

17. Ettinger B, Black DM, Nevitt MC, et al. Contribution of vertebral deformities to chronic back pain and disability. The Study of Osteoporotic Fractures Research Group. J Bone Miner Res 1992;7:449-56.

18. Huang C, Ross PD, Wasnich RD. Vertebral fracture and other predictors of physical impairment and health care utilization. Arch Intern Med 1996;156:2469-75.

19. Matthis C, Weber U, O'Neill TW, Raspe H. Health impact associated with vertebral deformities: results from the European Vertebral Osteoporosis Study (EVOS). Osteoporos Int 1998;8:364-72.

20. Kostova V, Koleva M. Back disorders (low back pain, cervicobrachial and lumbosacral radicular syndromes) and some related risk factors. J Neurol Sci 2001;192:17-25.

21. Zhao LJ, Liu YJ, Liu PY, Hamilton J, Recker RR, Deng HW. Relationship of obesity with osteoporosis. J Clin Endocrinol Metab 2007;92:1640-6.

22. Janicka A, Wren TA, Sanchez MM, et al. Fat mass is not beneficial to bone in adolescents and young adults. J Clin Endocrinol Metab 2007;92:143-7.

23. Hsu YH, Venners SA, Terwedow HA, et al. Relation 
of body composition, fat mass, and serum lipids to osteoporotic fractures and bone mineral density in Chinese men and women. Am J Clin Nutr 2006;83:146-54.

24. Reid IR. Relationships between fat and bone. Osteoporos Int 2008;19:595-606.

25. Cornish J, Callon KE, Reid IR. Insulin increases his- tomorphometric indices of bone formation In vivo. Calcif Tissue Int 1996;59:492-5.

26. Felson DT, Zhang Y, Hannan MT, Anderson JJ. Effects of weight and body mass index on bone mineral density in men and women: the Framingham study. J Bone Miner Res 1993;8:567-73. 